\title{
Commentary
}

\section{Ki: A Key to Transform the Century of Death to the Century of Life}

\section{S. Tsuyoshi Ohnishi}

\author{
Philadelphia Biomedical Research Institute, King of Prussia, PA 19406, USA
}

This is my response to the commentary written by Mr James Flowers with the title of 'What is Qi?' in the issue 4 of Vol.3 (2006) of eCAM. I will explain my opinions regarding the importance of $\mathrm{Ki}$ research, philosophical aspects of $\mathrm{Ki}$ and a possible role of $\mathrm{Ki}$ now and in the future.

Keywords: butterfly effect-chaos-Ki energy-linear philosophy-Nishino Breathing Methodnonlinear philosophy

\section{Introduction}

I would like to thank Mr James Flowers for his interesting commentary on Qi and his discussion of our work on Ki (called Qi in Chinese) (1). I was impressed with his deep philosophical considerations and beautiful poetic explanation of Qi as being behind everything. In the same issue, Dr E.L. Cooper, the Editor-in-Chief of $e C A M$, wrote that, in the early stage of the development of this journal, more philosophically and historically oriented manuscripts were received for review than those of original scientific work. He believes that both philosophical consideration and rigorous scientific work should be blended with each other for the healthy growth of science (2). Therefore, he was happy to notice that we contributed new experimental work on $\mathrm{Ki}$, and subsequently, our papers stimulated the philosophical discussion by Flowers. These two articles prompted me to write this article covering the nature of $\mathrm{Ki}$ as well as its philosophical aspects and the significance in the modern civilization.

I am thoroughly grounded in modern science, but my roots are in Eastern culture. (I was born in Japan and received education there.) I have a degree in biophysics, but I also have a black belt in Aikido and taught it in the USA from 1967. I learned about the Nishino Breathing Method (NBM) through Mr Kozo Nishino's publications

For reprints and all correspondence: S. Tsuyoshi Ohnishi, PhD, Philadelphia Biomedical Research Institute, Suite 250, 100 Ross Road, King of Prussia, PA 19406, USA. Tel: 610-688-6276; Fax: 610-254-9332; E-mail: stohnishi@aol.com
[(3-5) and many other Japanese books]. I first attended the school of NBM in Tokyo 10 years ago, and 3 years later, the collaboration with $\mathrm{Mr}$ Nishino started in order to find a scientific basis for $\mathrm{Ki}$. After several years of struggle, our first paper on the effects of $\mathrm{Ki}$ on cultured cancer cells was published (6), which Flowers cited in his commentary. Subsequently, we published two more papers $(7,8)$. I would like to start my response with the data in these two papers, because they may have answers to some of the questions which he raised in his article. Then, I will discuss some philosophical aspects of $\mathrm{Ki}$, and a possible role of the scientific study of $\mathrm{Ki}$ effects in broadening our Western perspectives.

\section{Ki Effects Can be Reproduced by the Students of Mr Nishino}

Flowers questioned whether the observed Ki phenomena are limited to $\mathrm{Mr}$ Nishino alone. This is a good point. If only one person is effective, but nobody else, then this is a paranormal phenomenon and not a fitting object of science. Yes, other people can reproduce Ki phenomena, too. Dozens of instructors in two schools (Tokyo and Osaka) of NBM and some students can emit Ki. We reported that S.T. Ohnishi and T. Ohnishi could reduce the growth of cultured cancer cells, although their effects were not as strong as that of Mr Nishino (7). In that report, we also described that S.T. Ohnishi could move other students with his $\mathrm{Ki}$, but his effect was weak 
and worked on a small number of students who are very sensitive to $\mathrm{Ki}$.

\section{Can Ki be Measured Quantitatively?}

Flowers asked whether we could measure $\mathrm{Ki}$ using our modern technology. This is a million dollar question. Many investigators have tried, and reported that Ki may be an infrared radiation, a magnetic field, an electrostatic field, sound waves and so on $(9,10)$. This looks like reports from many blind persons touching different parts of an elephant. We do not even know the qualitative nature of $\mathrm{Ki}$ yet, not to mention quantitative methods of measuring it.

\section{Energy and Entropy Aspects of Ki}

Flowers was asking whether $\mathrm{Ki}$ may be an 'energy'. Many believe it is. However, it is interesting to note that there is a subtle difference in understanding between the Chinese and the Japanese. The former seems to believe that it is a 'substance' or 'matter' flowing in and through our bodies, and that it can be emitted from the body of a Qigong healer. In contrast, the Japanese considers that it is a form of energy. An interesting concept was published by Shinagawa's group that treats $\mathrm{Ki}$ as a form of 'information' $(11,12)$. Flowers considers $\mathrm{Ki}$ as being about 'relationships and patterning'. These concepts are another way of describing 'information'.

The most interesting practice in NBM is called the Taiki-practice (a method developed by Kozo Nishino, the founder of the Nishino Breathing Method, to develop the level of individual's $\mathrm{Ki}$ through the $\mathrm{Ki}$ communication between an instructor and a student). In a class room, a student stands in front of a wall (which is covered with a soft cushion to absorb the shock when the student hits the wall) with his/her back facing the wall. The student and an instructor touch their hands (right to right or left to left). Then, they try to send Ki alternately from their hands. When the instructor sends strong $\mathrm{Ki}$, the student feels the 'energy' and steps or runs backward toward the wall. With this practice, students can learn how to raise the level of their $\mathrm{Ki}$ energy. It is important to note that after training, the effect is the same even when the student is blindfolded and the instructor sends Ki without touching student's hand. Through the study on the Taiki-practice, we raised the possibility that Ki-energy may carry information, and that the information is in a form of 'entropy' (7). If Ki consists of simple energy, then, Ki effects might be mimicked by an instrument. However, if $\mathrm{Ki}$ involves entropy, it may be difficult to artificially reproduce the entire Ki effect.

\section{Thermal Effect of Ki}

It has been known that Chinese Qigong healers can emit infrared radiation from their hand $(9,13)$. Thermographical studies demonstrated that skin temperature was raised by $3-4^{\circ} \mathrm{C}$ when exposed to Qi emitted from Qigong healers (10). When we receive Ki from Nishino, instructors of his school or from students who practice for many years, we feel a warm sensation. Therefore, we assumed that a component of Ki may be infrared radiation. We used either a visible bandpass filter $(360-760 \mathrm{~nm})$ or a near infrared filter $(0.8-2.7 \mu \mathrm{m})$, and placed it in front of Ki-emitter's fingers. It was interesting to note that both biochemical effects and Taiki-effects were blocked by the visible bandpass filter, but not by the near infrared filter $(7,8)$. We interpreted the result to mean that infrared radiation in the range of $0.8-2.7 \mu \mathrm{m}$ is responsible for both biochemical and Taiki reactions. In our following paper using mitochondria, we measured a temperature change of a mitochondrial suspension when it was exposed to $\mathrm{Ki}$. The temperature did not change when the suspension was exposed to $\mathrm{Ki}$ through the visible bandpass filter, but it was raised by $0.02^{\circ} \mathrm{C}$ when it was exposed through the near infrared filter (8). This again supports the idea that $\mathrm{Ki}$ has an infrared radiation component.

\section{Healing Effects of $\mathbf{K i}$}

Qi has been used as a healing technique in China for 4000 years. In Japan, $\mathrm{Ki}$ has been known to have a healing effect at least for 1500 years. The school of NBM is not set up to offer clinical therapy to its students. However, in two emergency situations when students were injured by accidents, Nishino personally sent Ki for $10-45 \mathrm{~min}$ to the injured part of their body. Each student was relieved from the pain, and subsequently, experienced an unusually quick recovery $(14,15)$. A case was known that Nishino's $\mathrm{Ki}$ healed a sprained finger of a non-practitioner in $10 \mathrm{~min}(16)$.

\section{Attempts to Find the Mechanism Behind the Healing Effects of $\mathbf{K i}$}

Why do students of NBM continue to attend the class (many of them once a week, but some of them more often) for 10 or even 15 years? Because they feel healthier, or because they are enjoying life with a feeling of more youthful spirit. Through our study, students were shown to have higher immune activity and lower stress levels (17). Some students overcame cancer themselves by attending the class almost everyday to lift their $\mathrm{Ki}$ level. We believe that this experience may be related to our in vitro results that $\mathrm{Ki}$ inhibited the growth of cancer cells (6). As to the anti-aging effect of NBM, Mr Nishino has long proposed that Ki may stimulate 
mitochondria to become more active, and thus, to provide more energy to the cells. We demonstrated that in isolated rat liver mitochondria, the respiratory control ratio was protected from deterioration by $\mathrm{Ki}$, and lipid peroxidation was inhibited by $\mathrm{Ki}$ (8). These results suggest that $\mathrm{Ki}$ may inhibit apoptosis of the cells in our body, thereby inhibiting aging. Some students were shown to have higher bone density than their age- and gender-matched contemporaries who do not practice NBM (18). Through in vitro tests, we found that $\mathrm{Ki}$ may be beneficial in preventing osteoporosis (accepted for publication in $e C A M$ in 2007). We are accumulating data on health-related benefits of NBM, and also, trying to correlate this with the molecular and cellular mechanisms of $\mathrm{Ki}$ effects.

\section{Can Ki Cause an Undesirable Action?}

Flowers raised an interesting point as to whether Qi (or Ki) can only cause a desirable action. Since he is proficient in Chinese traditions, he may be discussing Yin and Yang (negative and positive) aspects of Qi.

As far as I know of, I have not heard of any negative effects of $\mathrm{Ki}$ in NBM during my 10 years association with the school. For this reason, Nishino's Ki seems to be very positive. I believe that the goal of our life is to have a healthy, happy life. A human being is happy and healthy when he/she is doing something good and enjoyable to himself/herself and, at the same time, beneficial to others. In other words, when individuals follow this humanistic path, they will become happy. If someone keeps following a negative or evil path, this person eventually loses good fortune, weakens his/her life force and becomes unhappy. I believe in the positive ethical doctrine that a human's inborn nature is fundamentally good. In this sense, I am an optimist, and I believe that NBM is a natural and humanistic way.

\section{Is Ki Related to Meditation?}

Since the practice of NBM includes slow breathing with the eyes half closed, it looks like a form of meditation. Actually, a Zen master, who is a high priest of a Zen temple in Japan, practices NBM. He wrote that NBM helped him to understand and master Zen meditation (16). We discussed the possibility that meditation deals with the world of 'sub-consciousness' developed by Freudian psychology, while NBM may be related to the world of 'Collective unconsciousness' of Jungian psychology (7).

\section{Philosophy and Science}

Philosophy has been considered as the mother of all aspects of human culture, and indeed, science originated from philosophy. It took more than 2000 years until modern science proved Democritus' atomic theory. As Flowers mentioned, in the Christian West, God was the center of everything as opposed to Ki (or Qi) being the center of everything in the East. Modern science and technology were largely developed in the West, where people were taught that the plants and animals on earth were to serve human beings. This seems to be related to the destruction of the ecosystem of which everyone is now more aware. In contrast, it has been taught in the East that the human being and its environment are one: Life is created from the environment, and when life ceases, it is returned to the environment.

In this sense, it can be said that modern science lacks humanistic philosophy. Science and technology became slaves of human desire, egoism and the pursuit of monetary gain. As a result, the pursuit of happiness was forgotten. Common problems in the world today, such as the fragmentation of the family, increase of mental diseases, depression and suicide, homicide, violence, terrorism and war (which is the ultimate form of homicide and terrorism) are the result of the loss of concern with 'happiness'. In other words, the lack of guiding philosophy caused the loss of human dignity. This problem was mentioned in our first paper on Ki (17). We expressed the hope that the study of $\mathrm{Ki}$ might help to unite more aspects of Eastern and Western philosophy

\section{A Paradigm Shift from 'Linear' to 'Nonlinear'}

The foundation of physics was laid by Descartes (15961650) who asserted that the movement of an object (for example, a canon ball) can be described by mathematical equations in Cartesian coordinates, and it is not influenced by the human mind. This separation of body and mind helped to develop mathematics- and technologyoriented modern culture. However, as I mentioned earlier in this commentary, this separation of mind may also have contributed to the lack of humanism in modern civilization.

Descartes' mathematical physics was completed by Newton (1642-1727) who developed a mathematical technique called 'differentiation'. It is based upon the concept that a part of a 'curve' can be considered as a 'straight line' when we look at an infinitesimally small portion of the curve. This can be regarded as an example of the Greek 'reductionism' in which a complex phenomenon can be reduced to simple, fundamental components. Using this mathematical tool, and based upon his discovery of universal gravitation, Newton completed a mechanistic world-view of the universe. His greatest success was that he was able to predict the movement of heavenly bodies, such as the sun, planets, moons and comets. The fact that Newtonian physics can predict the occurrence of solar and lunar eclipses with an accuracy 
less than a second, and predict the return of the comets with the orbital time span of hundreds of years symbolized the success of mechanistic and deterministic world-view of classical science.

The reason why Newton's physics was so successful in predicting the future motion of heavenly bodies was that the motion can be described by linear equations. Since the success was so great, no one paid attention to the finding of Poincaré (1854-1912), who discovered that the movements of three planets with similar sizes are unpredictable (because the motion is expressed by nonlinear equations). It was as recently as 1961 that the importance of the unpredictability in a nonlinear system was 're-discovered' by Lorenz. He was experimenting with a nonlinear weather model on his computer. He was surprised to find that a change of the initial conditions, which is as small as only $1 / 5000$ different from the previous run, yielded a dramatically differing weather pattern (19). He called such an extreme sensitivity of a nonlinear system to initial conditions a 'butterfly effect'. His result became well known as a joking notion that 'a butterfly stirring the air today in Peking can transform storm systems next month in New York'. With his discovery, the Newtonian era of the predictability of a linear system ended, and it was replaced by the unpredictability of a nonlinear system, and the new science called 'chaos' was born $(19,20)$. As I will describe in the rest of this article, this new science seems to hold a key in understanding Ki.

\section{Ki May be Understood as a Butterfly Effect in a Nonlinear System}

The energy emitted from the hands or fingers of a human being may be very small. Why can such a small energy create a tangible effect? We speculated on the possibility that $\mathrm{Ki}$ may cause a minute change in a protein or nucleotide component upstream in the signal transduction pathway. Then, the change would be amplified a million times by a 'cascade' reaction in the signal transduction mechanism (7). The amplification feature of the cascade reaction lies in its nonlinear nature. Therefore, we believe that Ki effects are manifested by the 'butterfly effect' of the nonlinear system involved.

\section{Ki May be Another Name of 'Life'}

As Flowers beautifully described, Ki may represent the entity of life itself. Then, the understanding of Ki may shed light on other aspects of biological sciences. When Darwin (1809-82) proposed the theory of evolution, many religious figures opposed his view. We thought that that battle was over a long time ago, but at least in the USA, it was not. Certain groups of people still oppose teaching the theory of evolution in the biology course in public school. Some people assert that an alternative 'designer theory' should also be taught in public school. Interestingly enough, the strongest opposition to the theory of evolution comes from the scientific community, not from the religious circle. Certain people argue that a big event, for example, the creation of complex organs (such as the brain or the eyes) cannot be explained as the result of the accumulation of a small 'mutation' and 'natural selection'. If the entire change took place as the accumulation of small, step-by-step changes, then, intermediate species which correspond to each step should be found. They argue that 'intermediate species' between the unevolved and the fully evolved were never found. The theory of nonlinearity may have an answer to this long-lasting dispute.

A fascinating feature of a nonlinear system is its complex behavior, namely: (i) unpredictability of the future, (ii) extreme sensitivity to the initial condition and (iii) synchronization between two nonlinear systems. In other words, anything can happen over the life system because its essence is nonlinear. It has been proposed that 'order' may be created from the nonlinear chaotic system (20). The spontaneous creation of life and its evolution on earth may be explained by the complexity and the infinite potential which a nonlinear complex system possesses $(21,22)$. From the study of the evolution of an 'artificial life' (life-like behavior of a model on the computer screen), it was found that big, sudden changes occur sporadically in the nonlinear 'evolution' model (23). If similar phenomena take place in the evolution of species on earth, then, we can explain why 'intermediate species' cannot be found. In summary, the nonlinear theory proposes that no 'designer' would be needed for creation and evolution.

\section{Taiki-Practice May be a 'Synchronization' Between Two Nonlinear Systems}

The Taiki-practice in NBM is considered to be a form of communication between two individuals without depending on our five senses (7). From the nonlinear aspects of $\mathrm{Ki}$, the Taiki-practice may be understood as an example of a 'synchronization' between two nonlinear systems (24). Flowers mentioned that the speed of Qi investigation seems to have slowed down in recent years. I would like to suggest that the reasons may be: (i) everyone was trying to understand $\mathrm{Ki}$, which essentially belongs in the realm of nonlinearity, through the framework of linear thinking; (ii) nonlinearity occurs when every part of a system is related to each other. This is exactly how our body is built. Then, the traditional 'reductionist' approach does not work, because this approach tries to dissect the system into pieces with a hope that each feature of the system is composed of fundamental elements. This is essentially a linear approach. 
However, in a nonlinear system, each component is related to all other components, and the relationship or the relatedness is the most important factor. Therefore, it would be impossible to arrive at the 'fundamental elements'. We need a paradigm shift in our thinking from linear to nonlinear in order to understand $\mathrm{Ki}$.

\section{'Linear Philosophy' and 'Nonlinear Philosophy'}

Western civilization has been built on two pillars, namely, Greek reductionism and the Christian-Newtonian determinism. Both pillars are linear concept. In contrast, Eastern culture has been shaped along a concept of 'dependent origination' proposed by Gautama (6th century $\mathrm{BC}$ ). This concept holds that each component in the universe (including animate and inanimate) is intimately related with all other components. He asserted that each and every human being is equal, and that there is no absolute being. The most important feature of this system is that it is nonlinear. Therefore, the future of the system is essentially unpredictable. The difference between the cultures in the West and the East may be described by the difference between 'linear philosophy' and 'nonlinear philosophy'. Since Ki phenomena are essentially nonlinear, a straightforward application of linear philosophy may not be effective in its study. We hope that the study of Ki phenomena may help bridge some of the apparent difference between Western and Eastern culture.

\section{The Importance of Ki Research in the 21st Century}

\section{Shift from the Western Cartesian Paradigm}

The results of Ki studies force us to re-examine the very foundation of modern sciences which has been based upon Descartes' assertion that seperates body and mind. As we wrote in a previous paper (7), Ki-phenomenon is based upon the findings that our mind seems to influence the motion or vibration of a molecule, and as a result, it creates a motion of the entire human body. It is a challenge to traditional scientific thinking. Therefore, further analysis of $\mathrm{Ki}$ may help to create a Copernican paradigm shift in science. This shift may help better address some of problems in our civilization today.

\section{Paradigm Shift from Linear to Nonlinear}

$\mathrm{Ki}$ phenomenon seems to be characteristic to the nonlinear nature of life. If so, the study of Ki may help deepen our understanding on our life and the universe itself. Since $\mathrm{Ki}$ is related to our life activity, the understanding of $\mathrm{Ki}$ would contribute to the elucidation of the beautiful nature of life itself. I hope this shift from the linear, deterministic Newtonian world-view to a nonlinear, chaos-based world-view will highlight the infinite potential of each and every human being, and help affirm the dignity of life. This is so badly needed in today's troubled world.

\section{Shift from the 'Century of Death' to the 'Century of Life'}

It is said that more than 60 million people were killed during the 20th century because of political turmoil, differences in ideology or religion, civil wars and two world wars. Which incident did contribute the most in shaping the past century as the 'Century of Death?' Toward the end of the past century, the TIME magazine selected 100 most important incidents of that century. At the top was the release of nuclear energy. The development of the theory of relativity and quantum physics resulted in the success of the release of nuclear energy. The use of two atomic bombs killed more than 300000 people instantly followed by the slow death of a million more.

With the new century, everyone hoped that it would be a happy, peaceful one. However, things seem to be running backward, and even worse. What can we do about it? I believe that we have to undergo a paradigm shift from an old mechanistic and deterministic CartesianNewtonian world-view (linear world-view) to a new world-view in which the infinite potential of the human being is praised and admired (nonlinear world-view). Further development and understanding of Ki may help round out our belief in technology-oriented modern science which lacks humanistic aspects. This may help to transform the 'Century of Death' to the 'Century of Life'. The 19th century was the age of the 'industrial revolution' which was symbolized by an invention of a steam engine. The 20th century is the age of 'nuclear energy'. Then, what would make the 21 st century more humanistic so that history might regard it as a century of life? The pursuit of studies on Ki or Qi might be a positive step.

In conclusion, $\mathrm{Ki}$ phenomenon is not paranormal. It is a normal and real phenomenon and can be the object of rigorous scientific study. If the question is posed, 'Why do you study Ki?' I will answer, as a famous mountain climber once said, 'Because it is there!'

\section{References}

1. Flowers J. What is Qi? Evid Based Complement Alternat Med 2006;3:551-2.

2. Cooper EL. eCAM: on to Year 4. Evid Based Complement Alternat Med 2006;3:1-4

3. Nishino K. The Breath of Life: Using the Power of Ki for Maximum Vitality. Tokyo, New York, London: Kodansha International, 1997.

4. Nishino K. Le Souffle de Vie, Utiliser le Pouroir du Ki. Paris: Guy Tredaniel Editeur, 1998.

5. Nishino K. Il Respiro Della Vita, La massima vitalita dalla forza del $K i$, Esercizi di Respirazione facili, effieaci, completamente illustrati. Rome, Italy: Edizioni Mediterranee, Via Flaminia, 1999. 
6. Ohnishi ST, Ohnishi T, Nishino K, Tsurusaki Y, Yamaguchi M. Growth inhibition of cultured human carcinoma cells by Ki-energy (Life Energy): scientific study of Ki-effect on cancer cells. Evid Based Complement Altern Med 2005;2:387-93.

7. Ohnishi ST, Ohnishi T. The Nishino Breathing Method and $\mathrm{Ki}$-energy (Life-energy): a challenge to traditional scientific thinking. Evid Based Complement Altern Med 2006;3:191-200.

8. Ohnishi ST, Ohnishi T, Nishino K. Ki-energy (Life-energy) protects isolated mitochondria from oxidative injury. Evid Based Complement Altern Med 2006;3:475-82.

9. Yuasa Y. The Body, Self-Cultivation and Ki-energy (translated by S. Nagatomo and M.S. Hull). Albany, NY: State University of New York Press, 1993.

10. Machi Y. The Science of Ki (in Japanese). Tokyo: Tokyo Denki University Press, 1993.

11. Kawano K, Koito H, Fujiki T, Shinagawa Y. EEG and topography during Chinese "Qigong" training. Neurosiences 1990;16:503-8.

12. Shinagawa Y. The Science of Qigong (in Japanese). Tokyo: Kobunsha, 1990.

13. Kiang T. Chinese "Nature Magazine": Chinese style. Nature 1978;275:697.

14. Nishino K. Super Power of Ki: Application of the Intelligence of the Cell (in Japanese). Tokyo: Jitugyono Nipponsha, Pub. Co., 1995.

15. Yumi K. The Ultimate Example of Nishino Breating Method: Everyday of Yumi Kaoru with Slim and Bouncing Body (in Japanese). Nishino K, (ed). Tokyo: TAKE Shobo Pub. Co., 2005.
16. Nishino K. The Discovery of $\mathrm{Ki}$ (in Japanese). Tokyo: Shodensha, 1989.

17. Kimura H, Nagao F, Tanaka Y, Sakai S, Ohnishi ST, Okumura K. Beneficial effects of the Nishino Breathing Method on the immune activity and stress level. J Altern Complement Med 2005;11:285-91.

18. Nishino K. The Nishino Breathing Method (in Japanese). In: Arita H, (ed). The Dictionary of Respiration. Tokyo: Asakura Book Publishing Co., 2006, 678-97.

19. Gleick J. Chaos: Making a New Science. New York, NY: Penguin Books, 1987

20. Waldrop MM. Complexity: The Emerging Science at the Edge of Order and Chaos. New York, London, Tokyo: Simon \& Schuster, 1992.

21. Kauffman S. The Origins of Order: Self-Organization and Selection in Evolution. Oxford, New York: Oxford University Press, 1993.

22. Kauffman S. At Home in the Universe: The Search for the Laws of Self-Organization and Complexity. Oxford, New York: Oxford University Press, 1995.

23. Levy S. Artificial Life: A report from the Frontier Where Computers Meet Biology. New York: Random House, Inc., 1992.

24. Strogatz S. SYNC: The Emerging Science of Spontaneous Order. New York: Hyperion, Inc., 2004.

Received December 31, 2006; accepted January 24, 2007 


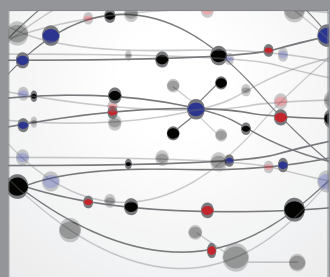

The Scientific World Journal
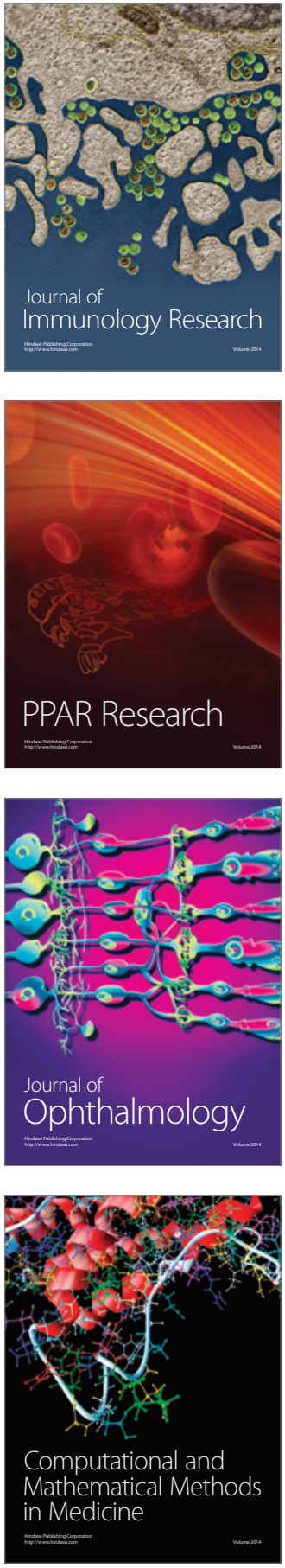

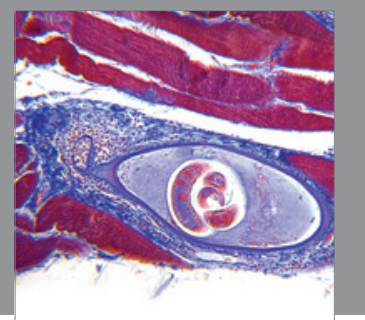

Gastroenterology

Research and Practice
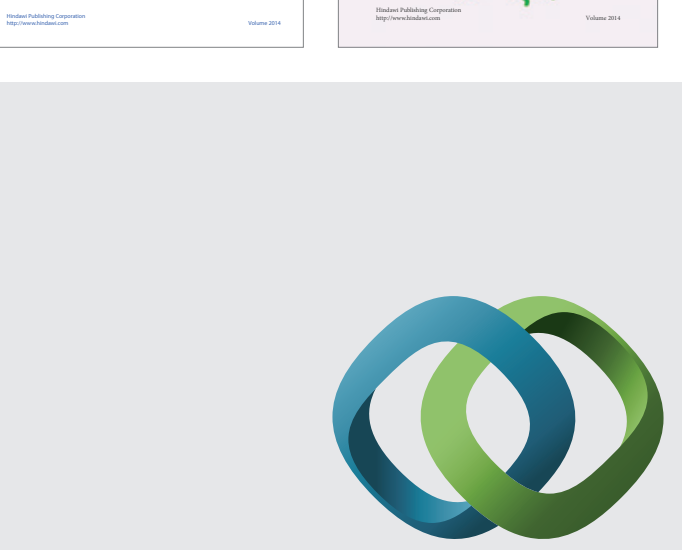

\section{Hindawi}

Submit your manuscripts at

http://www.hindawi.com
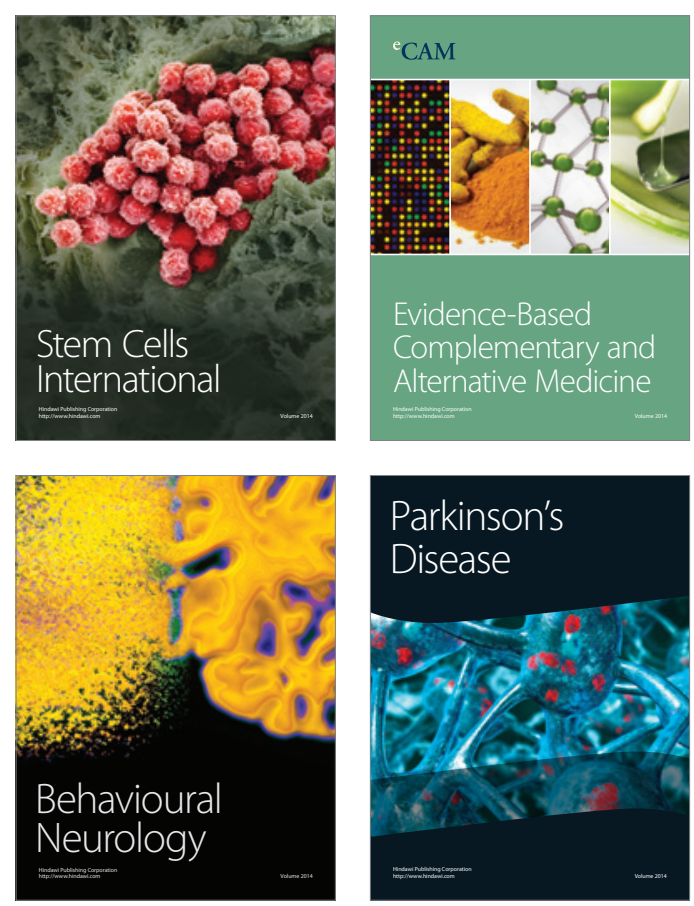

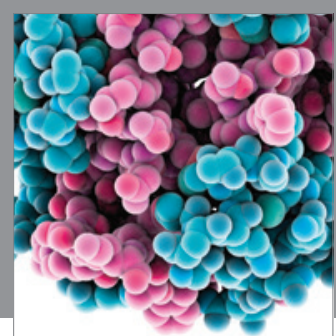

Journal of
Diabetes Research

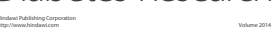

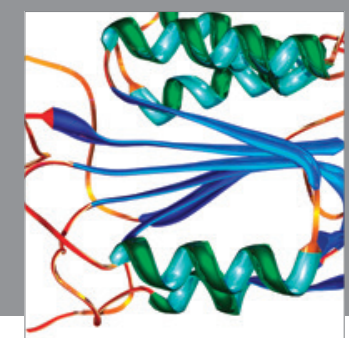

Disease Markers
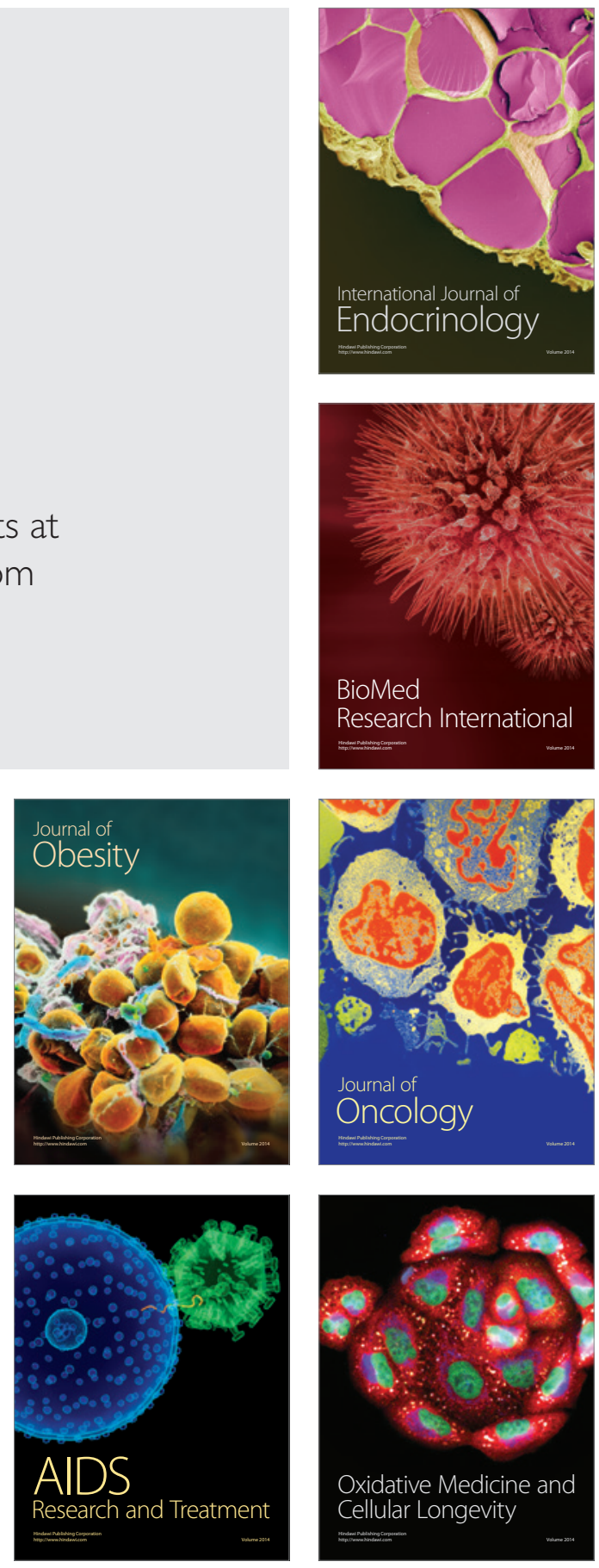